\title{
DEEP DESULFURIZATION BY ADSORPTION OF 4,6-DIMETHYLDIBENZOTHIOPHENE, STUDY OF ADSORPTION ON DIFFERENT TRANSITION METAL OXIDES AND SUPPORTS.
}

\author{
F. APARICIO ${ }^{1}$, E. CAMU' 1 , M. VILLARROEL ${ }^{2}$, N. ESCALONA ${ }^{3}$, P. BAEZA ${ }^{1 *}$

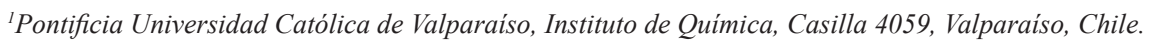 \\ ${ }^{2}$ Universidad Católica Silva Henríquez, General Jofré 462, Santiago, Chile. \\ ${ }^{3}$ Universidad de Concepción, Facultad de Ciencias Químicas, Casilla 160C, Concepción, Chile.
}

(Received: July 30, 2013 - Accepted: November 8, 2013)

\begin{abstract}
In this work the adsorption of 4,6-dimethyldibenzothiophene (4,6-DMDBT) on different supports $\left(\mathrm{SiO}_{2}, \mathrm{Al}_{2} \mathrm{O}_{3}\right.$, zeolite $4 \mathrm{~A}$, zeolite $13 \mathrm{X}$, natural zeolite, and activated carbon), incorporating on its surface different first series transition metal oxides at different content, was studied. The results indicate that the activated carbon presents a higher adsorption capacity than the other supports studied, which it is assumed to the large number of functional groups present on its surface. The incorporation of the first series transition metal oxides on support, induces in some cases the increase of the adsorption capacities of 4,6-DMDBT and these adsorptions capacities depend on metal content. Finally, the desulfurization by adsorption represents an alternative tool for the elimination of refractory sulfur compounds.
\end{abstract}

Keywords: Adsorption, supports, transitions metals, 4,6-Dimethyldibenzothiophene.

\section{INTRODUCTION}

In recent decades, numerous studies have been reported that over time, the air quality has been getting worse which predicts a unfavorable future; this is the main reason why the recovery of the air quality is one of the prevailing challenges to possible increases in gas emission to the atmosphere. ${ }^{1}$

The main air pollutants: primary and secondary are products of combustion of different sources of fossil fuels, especially petroleum that still remains the most widely used energy source by cities and industries. Therefore, within the various problems that have brought this excessive consumption are: global warming, poor air quality, perturbations to biogeochemical cycles and acid rain, among other. ${ }^{2}$ The latter has became very important and enhancement within environmental plans, due to its high impact on buildings, land and structures in corrosive processes, bringing countless losses.

Sulfur dioxide is a primary pollutant and reacts with different species present in the atmosphere, generating secondary pollutants, principally acid rain. The $73 \%$ of $\mathrm{SO}_{2}$ produced is by anthropogenic origin and is related with the combustion of petroleum and its derivatives. Hydrodesulfurization (HDS) is a conventional process for removing sulfur compounds; the HDS can adequately desulfurize sulfur compounds such as thiols, sulfides, disulfides, thiophenes, and benzothiophene, but it's less effective for remove dibenzothiophene (DBT), and its alkyl derivatives for example: 4-methyldibenzothiophene (4MDBT) and 4,6-dimethyldibenzothiphene (4,6-DMDBT) ${ }^{3-6}$. This process uses $\mathrm{Ni}-\mathrm{Mo} / \gamma-\mathrm{Al}_{2} \mathrm{O}_{3}, \mathrm{Co}-\mathrm{Mo} / \gamma-\mathrm{Al}_{2} \mathrm{O}_{3}$, or Ni-W/ $/-\mathrm{Al}_{2} \mathrm{O}_{3}$ catalysts, and operate under high temperature $\left(300-450^{\circ} \mathrm{C}\right)$ and pressure $\left(20-100\right.$ bar $\left.\mathrm{H}_{2}\right)$ conditions, resulting in the loss of about 10 octane number ${ }^{3-7}$.

Actual legislation for the use of gasoline or diesel, states that sulfur concentration should be below $0.1-0.2 \mathrm{ppm}$. To reduce diesel sulfur content from 500 to $15 \mathrm{ppm}$ by HDS, it was estimated that the size of the reactor would necessarily increase by a 7 factor. Another estimation ${ }^{8}$ showed that in order to reduce the level of sulfur in diesel from 300 to less than $10 \mathrm{ppm}$, it would be necessary to increase from 15 to 600 psi hydrogen pressure in the HDS reaction.

From exploited oil reservoirs, are extracted compounds with high molecular weight, because they are located within the later stages of use of the reservoirs and, in turn, the remaining fraction, will be even heavier. The sulfur in this fraction is associated with aromatic molecules of high molecular weight. In this case the conventional method for HDS would not be adequate, due to the high conditions that should operate the reactor and the inability of the catalysts for the treatment of this "Refractory Molecules".

Then, it is a fact that alternative methods are needed for desulfurization, which, should be advantageous and more efficient that the conventional process, this development has been taking enhancement and has now led to the emergence of several alternative methods, such as: adsorption to selective remove sulfur compounds ${ }^{7}$, ultrasonic desulfurization ${ }^{8}$, oxidative desulfurization ${ }^{9}$, and biodesulfurization ${ }^{10,11}$.

For the purpose of improving the efficiency of conventional desulfurization process is proposed the use of adsorption to remove refractory organic sulfur compounds, since several studies have shown that the refractory compounds especially 4,6-dimethyldibenzothiophene (4,6-DMDBT) bind tightly through the formation of $\pi$-complexes ${ }^{7,12}$, which is carried out through an electronic back bonding between species adsorbed to the surface of an adsorbent. This usually occurs between a transition metal, with the aromatic rings of the adsorbed species. The mechanism of $\pi$-complexation of the cations of an adsorbent may be the link between $\pi$ molecular orbitals of the sulfurized organic molecule, with an empty " $s$ " orbital, while " $d$ " orbitals can donate electron density to the $\pi^{*}$ molecular orbital of the aromatic rings for the molecule with sulfur. The main feature of the cations is to form a strong electronic bonding to achieve $\pi$-complexation and these are the ones that have an electronic configuration $n \mathrm{~d}^{\mathrm{X}} \mathrm{ns}^{0}(\mathrm{x}=5-10)$ these cations also possess an empty s orbital, capable of accept electron density, and the d orbitals with electrons available for donation, an example for this is the $\mathrm{Cu}(\mathrm{I})$ with a $[\mathrm{Ar}] 3 \mathrm{~d}^{10} 4 \mathrm{~s}^{0}$ electronic configuration ${ }^{7,12}$ However, to achieve an adsorption process these metal cations should have a suitable support.

In this study we evaluated, the performance of the different support as adsorbent of 4,6-DMDBT and also the incorporation of different transition metal oxides and metal content. Initially, the use of this mechanism as a supplement or alternative to conventional desulfurization (HDS) provides a great advantage to perform the adsorption at room temperature and pressure, so there not would be a loss of octane in fuel, in order to achieve the current emission standards for the combustion of fossil fuel. ${ }^{13}$

\section{EXPERIMENTAL}

\subsection{Preparation of the adsorbent}

The supports studied were: $\mathrm{SiO}_{2}, \gamma-\mathrm{Al}_{2} \mathrm{O}_{3}$, zeolite $4 \mathrm{~A}$, zeolite $13 \mathrm{X}$, natural zeolite, and activated carbon $\left(\mathrm{C}_{\mathrm{act}}\right)$, these supports were used in a particle size between 120 and 270 mesh, support samples were dried at $100^{\circ} \mathrm{C}$ for $2 \mathrm{~h}$ in a muffle to remove traces of water.

The adsorbents were prepared using the best support obtained in support adsorptions studies, by dry impregnation using an aqueous solution of each metal nitrate of first transition metal series ( $\mathrm{Mn}, \mathrm{Fe}, \mathrm{Co}, \mathrm{Ni}, \mathrm{Cu}$, and $\mathrm{Zn}$ ), containing the required amount of salt to render nominal concentrations of $4 \%$. After impregnation of support, the adsorbents were dried at $100{ }^{\circ} \mathrm{C}$ for $12 \mathrm{~h}$, and then calcined at $300^{\circ} \mathrm{C}$ for $4 \mathrm{~h}$ in a muffle furnace.

Another series of adsorbents for the best metal, obtained in different metal oxides adsorptions studies were prepared by metal impregnation of the best support with aqueous solution of metal nitrate; containing the required amount 
of salt to render $2 \%, 4 \%$ and $6 \% \mathrm{w} / \mathrm{w}$. The samples were dried at $100^{\circ} \mathrm{C}$ for 12 $\mathrm{h}$, and then were calcined at $300^{\circ} \mathrm{C}$ for $4 \mathrm{~h}$ in a muffle furnace.

\subsection{Samples characterization}

For specific area (BET) determination were taken $0.2-0.4 \mathrm{~g}$ of each sample, which were degassed at $120^{\circ} \mathrm{C}$ for $18 \mathrm{~h}$, reaching a final pressure of $1 \times 10^{-3} \mathrm{mmHg}$. Subsequently, the analysis was performed within a glass slide at $-196^{\circ} \mathrm{C}$, using an apparatus for volumetric nitrogen adsorption-desorption, brand Micromeritics ASAP-2010.

The analysis for each sample with metal was performed by ICP-OES to determinate the real content, in a Perkin Elmer Optima 7300V. 0.3 g were taken from the samples and melted in a Pt crucible with a $2: 1$ mixture of sodium carbonate and lithium tetraborate, the melted sample was transferred to a nitric acid solution for analysis.

Electrophoretic migration measurements were performed on a Zeta Meter, model 3.0, provided with an automatic transfer unit sample. In each measurement is used approximately $30 \mathrm{mg}$ of the sample suspended in $300 \mathrm{~mL}$ of $\mathrm{KCl}$ solution $1 \times 10^{-3} \mathrm{M}$. Between each point, the $\mathrm{pH}$ was adjusted with $0.1 \mathrm{M}$ $\mathrm{KOH}$ or $\mathrm{HCl}$ as required.

\subsection{Adsorption experiments}

Adsorption experiments were performed in a vertical Pyrex reactor equipped with a supporting glass porous disk. A bed of $\sim 500$ milligrams of different adsorbents was placed in the reactor. Prior to the determination of the adsorption capacity ( $\mathrm{A}_{\mathrm{c}}$ ), an activation process was performed for each adsorbent, when the adsorbent is constituted by $\mathrm{Cu}(\mathrm{I})$ or $\mathrm{Fe}(\mathrm{II})$ a $20 \mathrm{~mL} \mathrm{~min}{ }^{-1}$ flow of pure $\mathrm{O}_{2}$ was passed at $300^{\circ} \mathrm{C}$ for $30 \mathrm{~min}$, then the temperature was decreased with a $20 \mathrm{~mL} \mathrm{~min}^{-1}$ flow of Ar, later was circulated a $20 \mathrm{~mL} \mathrm{~min}{ }^{-1}$ flow of $5 \% \mathrm{H}_{2} / \mathrm{Ar}$ mixture, at $180^{\circ} \mathrm{C}$ for $30 \mathrm{~min}$. Finally, the temperature was lowered again to room temperature with a $20 \mathrm{~mL} \mathrm{~min}-1$ flow of pure Ar. For $\mathrm{Mn}(\mathrm{II}), \mathrm{Co}(\mathrm{II}), \mathrm{Ni}(\mathrm{II})$, and $\mathrm{Zn}(\mathrm{II})$, the treatment was performed only with a 20

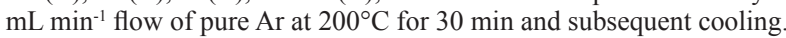

For the adsorption experiments, the liquid flow was driven into the reactor by means of a peristaltic variable flow mini-pump. The experiment was performed using an artificial mixture of $500 \mathrm{ppm}$ of 4,6-DMDBT in isooctane at a feed rate of $0.5 \mathrm{~mL} \mathrm{~min}^{-1}$. Samples were collected every $5 \mathrm{~min}$, until saturation was achieved; the total time and number of samples depended on the amount of adsorbent and its adsorption capacity.

The samples were analyzed by gas chromatography - flame photometric detector (GC-FPD) using a Shimadzu GC-2010 equipped with an SPB5 capillary column (L $30 \mathrm{~m}$, I.D. $0.25 \mathrm{~mm}$, Film $0.25 \mathrm{~mm}$, and the following conditions: detector at $250{ }^{\circ} \mathrm{C}$, injector at $150{ }^{\circ} \mathrm{C}$, and carrier flow, $15 \mathrm{~mL} \mathrm{~min}^{-1}$ $\left(\mathrm{N}_{2}\right)$. The column temperature was set to increase from $160{ }^{\circ} \mathrm{C}$ to $200{ }^{\circ} \mathrm{C}$ at a rate of $40{ }^{\circ} \mathrm{C} \mathrm{min}^{-1}$, and then at $220^{\circ} \mathrm{C}$ at $5{ }^{\circ} \mathrm{Cmin}^{-1} ; 0.5 \mathrm{~mL}$ of the sample volume was injected, using an autosampler, for each GC-FPD run. The limit detection was $2 \mathrm{ppm}$.

\section{RESULTS AND DISCUSSION}

\subsection{Effect of the type of surface}

Characterization results by the BET method of the different media studied are shown in Table 1, it is clear that the $\mathrm{C}_{\text {act }}$ has a larger apparent specific area and that the specific area of the other supports follow this increasing order: zeolite 4A, natural zeolite, zeolite $13 \mathrm{X}, \mathrm{SiO}_{2}, \gamma-\mathrm{Al}_{2} \mathrm{O}_{3}$.

Table 1: Specific area BET and adsorption capacities of 4,6-DMDBT of different supports studied; and apparent specific area of activated carbon.

\begin{tabular}{|c|c|c|}
\hline Support & $\begin{array}{c}\text { Specific area } \\
\mathbf{~ m}^{\mathbf{2}} \mathbf{g}^{-1}\end{array}$ & $\begin{array}{c}\text { Adsorption Capacity } \\
\text { (mg 4,6-DMDBT } \mathbf{~}^{-1} \mathbf{)}\end{array}$ \\
\hline$\gamma-\mathrm{Al}_{2} \mathrm{O}_{3}$ & 210 & 21.2 \\
\hline $\mathrm{SiO}_{2}$ & 195 & 0.4 \\
\hline Zeolite 4A & 22 & 0.2 \\
\hline Zeolite 13X & 134 & 8.4 \\
\hline Natural Zeolite & 47 & 2.5 \\
\hline Activated Carbon & 819 & 47.6 \\
\hline
\end{tabular}

By integrating the area under the adsorption curves the saturation adsorption capacities can be estimated. The adsorption capacity of 4,6-DMDBT for supports studied is shown also in Table 1. The results showed that within the supports studied, many of them have on their own (in the absence of metal) a certain adsorption capacity, which depends strongly on the specific area of each materials, finding that $\mathrm{C}_{\text {act }}$ has a higher adsorption capacity of 4,6-DMDBT (47.6 $\mathrm{mg} \mathrm{g}^{-1}$ of support) compared with the other supports studied. This higher adsorption capacity presented by $\mathrm{C}_{\text {act }}$, is related to the larger specific area that possesses and the presence of functional groups that confer acidity to the support, this also reflected in the isoelectric point close to 4.0, these two aspects produce more electronic back donation with the aromatic rings in the molecule of 4,6-DMDBT. On the other hand, alumina also exhibits considerable adsorption capacity, which would be related to the presence of $\mathrm{OH}$ functional groups, which may also have a certain adsorption capacity; likely alumina can also be used as support for metal oxides, but it is known its reactivity with oxides to form aluminate species ${ }^{14}$, which would not be related to any adsorption capacity. While the zeolites studied have a low adsorption capacity, are also important because they can be exchanged with any metal, however it should be considered obviously using another method of preparation of adsorbents, which departs from the conditions studied in this work, here we can delve into other work with other conditions.

\subsection{Effect of metal type}

The real content of each metal supported on activated carbon (the best support) determined by ICP-OES, are detailed in Table 2, which also provides the theoretical values. It is observed that the real contents are very close to the theoretical, although there is a small difference near to $10 \%$ of real content at worst, this can be attributed to a loss in the preparation process.

Table 2: Elemental analysis obtained by ICP-OES, ZPC and fraction of covered surface by metals, Breaking point (BP) and adsorption capacities of 4,6-DMDBT of $\mathrm{M}(4 \%)$ supported on activated carbon $(\mathrm{M}=\mathrm{Mn}, \mathrm{Fe}, \mathrm{Co}, \mathrm{Ni}$, $\mathrm{Cu}, \mathrm{Zn})$

\begin{tabular}{|c|c|c|c|c|c|c|}
\hline Sample & $\begin{array}{c}\text { Theorical } \\
\text { Metal } \\
\text { content } \\
\mathbf{( \% )}\end{array}$ & $\begin{array}{c}\text { Real } \\
\text { Metal } \\
\text { content } \\
\mathbf{( \% )}\end{array}$ & $\mathbf{Z P C}$ & $\mathbf{X}_{\mathbf{M}}$ & $\mathbf{B P}$ & $\begin{array}{c}\text { Adsorption } \\
\text { Capacity } \\
\text { (mg } \\
\text { 4,6-DMDBT } \\
\mathbf{g}^{-1} \mathbf{)}\end{array}$ \\
\hline $\mathrm{C}_{\text {act }}$ & -- & -- & -- & -- & 81.0 & 47.6 \\
\hline $\begin{array}{c}\mathrm{Mn}(4) / \\
\mathrm{C}_{\text {act }}\end{array}$ & 4 & 3.89 & 4.0 & -- & 117.2 & 64.9 \\
\hline $\begin{array}{c}\mathrm{Fe}(4) / \\
\mathrm{C}_{\text {act }}\end{array}$ & 4 & 3.56 & 4.8 & 0.32 & 113.1 & 80.9 \\
\hline $\begin{array}{c}\mathrm{Co}(4) / \\
\mathrm{C}_{\text {act }}\end{array}$ & 4 & 3.85 & 5.8 & 0.30 & 160.6 & 88.7 \\
\hline $\begin{array}{c}\mathrm{Ni}(4) / \\
\mathrm{C}_{\text {act }}\end{array}$ & 4 & 3.65 & 6.6 & 0.41 & 224.3 & 138.6 \\
\hline $\begin{array}{c}\mathrm{Cu}(4) / \\
\mathrm{C}_{\mathrm{act}}\end{array}$ & 4 & 3.80 & 5.5 & 0.27 & 48.5 & 27.2 \\
\hline $\begin{array}{c}\mathrm{Zn}(4) / \\
\mathrm{C}_{\text {act }}\end{array}$ & 4 & 3.56 & 4.6 & 0.12 & 40.4 & 23.1 \\
\hline
\end{tabular}

The zeta potential measurements, allow the determination of the isoelectric points (IEP) of pure solids (support and metallic oxides) and the respective zero charge point (ZPC) of mixtures, and even develop an idea of the species present in mixture surface ${ }^{15}$. The ZPC and fraction of covered surface $\left(X_{M}\right)$, calculated from measurements of the ZPC of all adsorbents and the IEP for $\mathrm{C}(4.0)$ and for each metal oxide $(\mathrm{MnO}=4.5, \mathrm{FeO}=6.5, \mathrm{CoO}=10.0, \mathrm{NiO}=10.3, \mathrm{CuO}=$ 9.5 and $\mathrm{ZnO}=9.2$ ), of the adsorbents studied are also shown in Table 2 .

First, we observe that for $\mathrm{Mn}(3.89) / \mathrm{C}_{\text {act }}$ is not possible to establish $\mathrm{X}_{\mathrm{M}}$, since the IEP of $\mathrm{C}$ and metal oxide have very close values. Furthermore, it is clear that $\mathrm{Ni}$ has a greater fraction of covered area $(0.41)$ compared with other metals at the same content $(\sim 4 \%)$. We also observe that $X_{M}$ has a volcano-type trend with a maximum in Ni to move forward in the period of the periodic table. This indicates that $\mathrm{NiO}$ is more dispersed that the other metals on the activated carbon surface, occupying a larger area. This is an important point because it has been reported that species with higher capacity electronic back donation are well dispersed species ${ }^{3,4}$. The determination of the adsorption capacities of 4,6-DMDBT, for the metals supported on $\mathrm{C}_{\text {act }}$ was realized on a content of $\sim 4 \%$, 
this content was chosen because in previous works it was observed that the ability to cause DBT and T adsorption depended on the amount of $\mathrm{Cu}$ species dispersed on $\mathrm{ZrO}_{2}^{3,4}$.

The breaking point, obtained in adsorption curve (adsorbed fraction $\mathrm{v} / \mathrm{s}$ eluted volume per $\mathrm{g}$ of adsorbent) and the results of the adsorption capacities of adsorbents $\mathrm{M} / \mathrm{C}(\mathrm{M}=\mathrm{Mn}, \mathrm{Fe}, \mathrm{Co}, \mathrm{Ni}, \mathrm{Cu}$, and $\mathrm{Zn})$ with a content of $\sim 4 \%$ are also shown in Table 2. It is clear that the adsorption capacity of the materials depends on the nature of the metal which acts as active site in the $\pi$ type adsorption, it should be noted that $\mathrm{C}_{\text {act }}$ has an adsorption capacity near to $48 \mathrm{mg}$ of 4,6-DMDBT $\mathrm{g}^{-1}$ of support, then if we observe the adsorption capacity for $\mathrm{Cu}$ and $\mathrm{Zn}$ adsorbents, we see that these are 27 and $23 \mathrm{mg} \mathrm{g}^{-1}$ support, lower than that the $\mathrm{C}_{\text {act }}$ (in the absence of metal), this may be due to: a) the difficulty to obtaining the oxidation states that meets the rule $(\mathrm{n}-1) \mathrm{d}^{\mathrm{x}} \mathrm{ns}^{0}$, especially for the case of $\mathrm{Cu}, \mathrm{b}$ ) it is possible that these metals may stabilize the electrons present in the $\mathrm{d}$ orbital, because they possess a complete orbital layer $\mathrm{c}$ ) incorporation of these metals, only lead to a coverage of functional groups presents in the surface of $\mathrm{C}_{\text {act }}$, who do have an adsorption capacity.

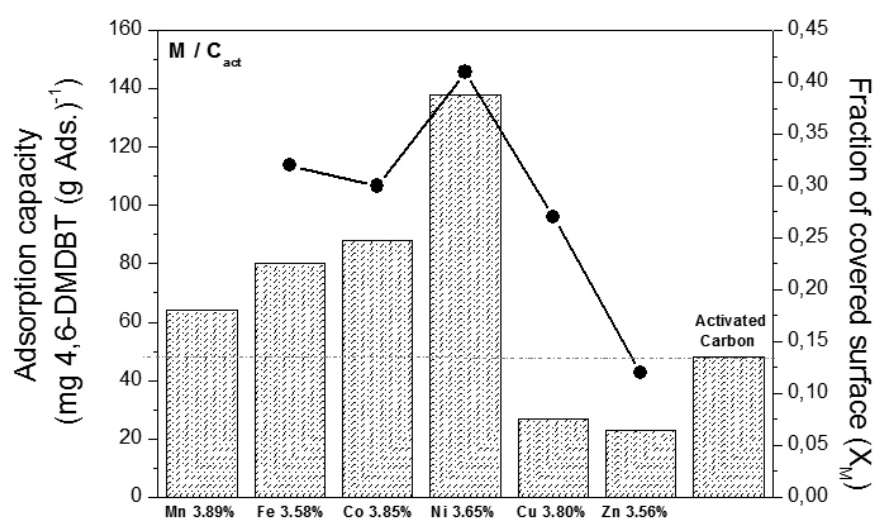

Figure 1: Adsorption capacities of 4,6-DMDBT (bars) and $X_{M}$ (line) for the adsorbents $\mathrm{M}(4 \%) / \mathrm{C}_{\text {act }}$ and activated carbon as reference.

Figure 1 illustrates the above results and also include $X_{M}$ values, thereby showing the relationship between the fractions of surface covered with the adsorptions capacities of different adsorbents, it can be established that as we move in the periodic position for studied metals, we observed a volcano type curve with a maximum in $\mathrm{Ni}$, mainly due to the stability for the +2 oxidation state, which has a configuration suitable for electronic $\pi$-complexation, this gives a greater number of $d$ electrons, for $\pi$-complexation and the metal is that has a larger surface on the support.

\subsection{Effect of metal content}

For the study of metal content on the adsorption capacity of 4,6-DMDBT, it was chosen the best adsorbent used within the previously studied, i.e. the adsorbent based on $\mathrm{Ni}$ supported on $\mathrm{C}_{\mathrm{ac}}$

First as expected, as well in the previous point the real contents are very close to the theoretical.

Specific area results for $\mathrm{C}_{\text {act }}$ and $\mathrm{NiO}(\mathrm{x}) / \mathrm{C}_{\text {act }}(\mathrm{X}=1.98,3.65$ or 5.65) are shown in Table 3, it is noted that the specific area $\mathrm{C}$ (in absence of $\mathrm{NiO}$ ) is high $\left(819 \mathrm{~m}^{2} \mathrm{~g}^{-1}\right)$, also it is observed a decrease of specific area by metal incorporation, this diminution is greater at content of $3.65 \%$, due to that for this $\mathrm{NiO}$ content the metal occupies a greater amount of specific area, but at mayor content, close to $6 \%$, the decrease is lower, probably due to a losing in the dispersion at higher nickel content.

In the same table we also appreciate that $\mathrm{X}_{\mathrm{M}}$ increases with the content of $\mathrm{Ni}$, for example from 0.08 to 0.35 at $\mathrm{NiO}$ content of 1.98 to $3.65 \%$ respectively, but at mayor contents $\mathrm{X}_{\mathrm{M}}$ decreases only slightly from 0.35 to 0.32 , for a content of 3.65 to $5.65 \%$, probably due to the formation of agglomerated $\mathrm{NiO}$ species on the surface of $\mathrm{C}_{\text {act }}$, and decreases the amount of disperses species; despite the high specific area of the support. This is confirmed by the slight increase of the specific area noted above with increasing the amount of $\mathrm{Ni}$ on activated carbon.
Table 3: Elemental analysis obtained by ICP-OES, ZPC and fraction of covered surface by metals, Specific areas measured by BET, Breaking point (BP) and adsorption capacities of 4,6-DMDBT of $\mathrm{Ni}(\mathrm{x} \%)$ supported on $\mathrm{C}_{\text {act }}$.

\begin{tabular}{|c|c|c|c|c|c|c|c|}
\hline Sample & $\begin{array}{c}\text { Theo- } \\
\text { rical } \\
\text { Metal } \\
\text { content } \\
\mathbf{( \% )}\end{array}$ & $\begin{array}{c}\text { Real } \\
\text { Metal } \\
\text { content } \\
\mathbf{( \% )}\end{array}$ & $\mathbf{Z P C}$ & $\mathbf{X}_{\mathbf{M}}$ & $\begin{array}{c}\text { Specific } \\
\text { area } \\
\mathbf{m}^{2} \mathbf{g}^{-1}\end{array}$ & $\mathbf{B P}$ & $\begin{array}{c}\text { Adsor- } \\
\text { ption } \\
\text { Capacity } \\
\text { (mg 4,6- } \\
\text { DMDBT } \\
\mathbf{g}^{-1}\end{array}$ \\
\hline $\mathrm{C}_{\text {act }}$ & -- & -- & -- & -- & 819 & 81.0 & 47.6 \\
\hline $\begin{array}{c}\mathrm{Ni}(2) / \\
\mathrm{C}_{\text {act }}\end{array}$ & 2 & 1.98 & 4.5 & 0.08 & 816 & 75.0 & 46.2 \\
\hline $\begin{array}{c}\mathrm{Ni}^{2}(4) / \\
\mathrm{C}_{\text {act }}\end{array}$ & 4 & 3.65 & 5.2 & 0.35 & 786 & 224.3 & 138.6 \\
\hline $\begin{array}{c}\mathrm{Ni}(6) / \\
\mathrm{C}_{\text {act }}\end{array}$ & 6 & 5.65 & 6.0 & 0.32 & 801 & 105.0 & 65.7 \\
\hline
\end{tabular}

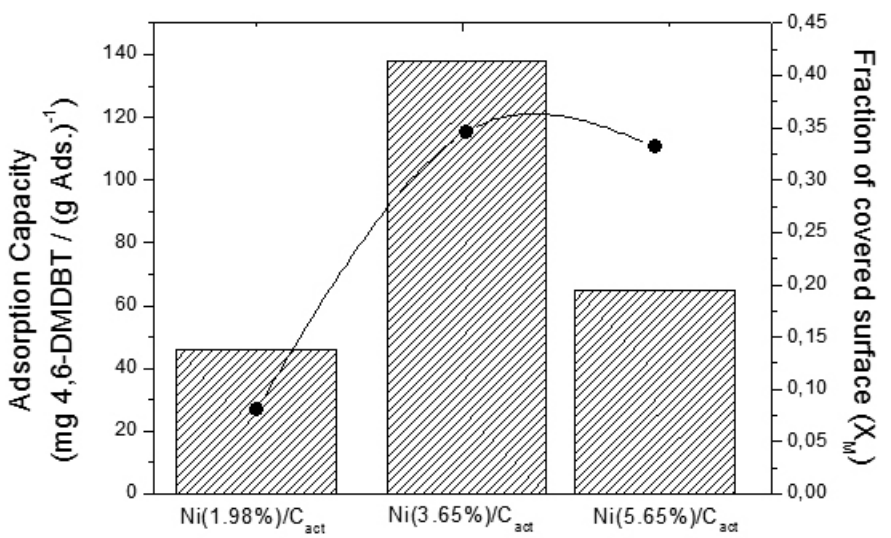

Figure 2: Dependence of adsorption capacity with the metal content and $\mathrm{X}_{\mathrm{M}}$ of $\mathrm{Ni}(\mathrm{x}) / \mathrm{C}_{\text {act }}$

To determine the dependence of the adsorption capacities with the metal content is evaluated the adsorption of adsorbents of $\mathrm{NiO}(\mathrm{x}) / \mathrm{C}$ ict in Table 3 . It clearly shows the differences in the breaking points (BP) that each sample possess, being clear that the adsorbent which has a higher BP is the adsorbent with $\mathrm{NiO}$ content close to $4 \%$. Table 3 also shows the adsorption capacity obtained from the adsorption curve and BP. The results in this table show us that the adsorption capacities of 4,6-DMDBT for $\mathrm{NiO}(\mathrm{x}) / \mathrm{C}_{\text {act }}$ adsorbent depends to the metal content, fraction of covered surface, the dispersion and the amount of high dispersed species of the metal on the surface.

\section{CONCLUSIONS}

Certain supports have an adsorption capacity even in the absence of a metal, within the studied highlights the activated carbon; due to its large number and variety of functional groups present on its surface. Moreover, the incorporation of a metal, generates an increase in the adsorption capacities of 4,6-DMDBT, whenever it can be obtained on the surface metallic species that have optimal and stable configurations for adsorption via $\pi$-complexation, thus the adsorption capacity of the adsorbent with activated carbon as support, depends on the nature of the metal to be incorporated, showing a volcanolike behavior with a maximum in $\mathrm{Ni}$, relating the adsorption capacities with electronic behavior (greater ability to stabilize optimal oxidation states) and covering properties over the support surface $\left(\mathrm{X}_{\mathrm{M}}\right)$. Undoubtedly, the metal content also plays an important role in the adsorption capacity of the adsorbent, finding an optimum content, which depends on the greater $\mathrm{X}_{\mathrm{M}}$, this is a point to improve in order to have a larger amount of $\mathrm{Ni}$ and covering major support surface, this can be achieved by changing the method of preparation of the adsorbent.

Adsorntive desulfurization is presented as an alternative tool for the HDS process for removing sulfur compounds, especially for the refractory 
molecules.

This work has been financed under FONDECYT Project No 11100165 , and DI 125.760 Pontificia Universidad Católica de Valparaiso.

\section{REFERENCES}

1. World Health Organization in Air quality guidelines for particulate matter ozone, nitrogen dioxide and sulfur dioxide, Denmark, 1, 484, (2006).

2. M. Hök, X. Tang, Energy Policy 52, 797 (2013).

3. P. Baeza, G. Águila. F. García, P. Araya, Catal. Commun. 9,751 (2008).

4. P. Baeza, G. Aguila, G. Vargas, J. Ojeda, P. Araya, Appl. Catal. B: Environmental 111, 133 (2012).

5. B.C. Gates, J.R. Katzer, G.C.A. Schuit, Chemistry of Catalytic Processes, McGraw Hill, New York, 1979.

6. A. Avidan, M. Cullen, National Petroleum \& Refiners Assoc. Annual Meeting. Washington, D.C., March 2001; Paper AM-01-55.
7. M. Villarroel, P. Baeza and F. J. Gil-Llambías, J. Chilean Chem. Soc. 55, $\mathrm{N}^{\mathrm{o}} 4,283,(2010)$

8. L. Wang, Y. Chen, L. Du, S. Li, H. Cai, W. Liu, Fuel 105, 353 (2013).

9. J. Becerra-Hernández, H. Gómez, J.Navarro, L. Cedeño, Rev. Mex. Ing. Qca., 5, 52 (2006).

10. M. Dinamarca, C. Ibacache-Quiroga, P. Baeza, S. Gálvez, M. Villarroel, P. Olivero, J. Ojeda, BioRes. Tech.,101, 2375 (2010).

11. M. Soleimani, A. Bassi, A. Margaritis, BioTech. Adv. 25, 570 (2007).

12. Arturo J. Hernández-Maldonado and Ralph T. Yang, Catal. Rev. 46, 111 (2004).

13. C. Satterfield in Heterogeneous catalysis in industrial practice, $2^{\text {nd }}$ ed., USA, Krieger Pub. 1, 554 (1991).

14. P. Bolt, F. Habraken,J. Geus, J. Solid State Chem.135, 59 (1998).

15. V. Bhandari, C. Ko, J. Park, S. Han, S. Cho, J. Kim, Chem. Eng. Sci., 61, 2599 (2006). 